Young $L$ and Ansell N (2003) 'Young AIDS migrants in Southern Africa: policy implications for empowering children' AIDS Care I5(3) 337-345

\title{
Young AIDS migrants in Southern Africa: policy implications for empowering children
}

Dr. Lorraine Young

Lecturer in Human Geography

and

Dr. Nicola Ansell

Lecturer in Human Geography

Department of Geography and Earth Sciences

Brunel University

Kingston Lane

Uxbridge UB8 3PH

Tel: ++44 (0) 1895203215

Fax: ++44 (0) 1895203217

Email: lorraine.young@brunel.ac.uk; nicola.ansell@brunel.ac.uk 
Young L and Ansell N (2003) 'Young AIDS migrants in Southern Africa: policy implications for empowering children' AIDS Care I5(3) 337-345

\title{
Young AIDS migrants in southern Africa: policy implications for empowering children
}

\begin{abstract}
Many AIDS-affected children in southern Africa engage in migration when household members fall sick or die from AIDS, or because they are sent to assist relatives. Despite this, little attention has been paid to the consequences of these movements for children's lives. Multi-method research, conducted in Lesotho and Malawi, revealed that children sent to live with kin commonly move over long distances and between urban and rural areas. They are generally not consulted or informed about these migrations and face a range of associated difficulties, particularly with integrating into new families and communities. Severed family ties exacerbate the difficulties faced by children who end up in institutions or on the streets.
\end{abstract}

This paper advocates that policy approaches for those affected by AIDS should be childrencentred and take into account the implications of migration at three levels. First, many of the difficulties children face could be overcome if they were familiar with the place and people they were moving to. Second, children would be better able to cope with new situations if they were included in family discussions with decision-makers regarding their migration preferences. Third, maintaining ties with kin would ensure that children do not become distanced from their family and cultural heritage, which is essential for post-institutional support. 


\title{
Young AIDS migrants in southern Africa: policy implications for
}

\section{empowering children}

\author{
Introduction
}

Southern Africa is currently the global region worst affected by the AIDS pandemic (UNAIDS 2000b). Poverty, related to structural conditions, has fuelled the spread of AIDS in recent years to unprecedented levels, while limited access to health services has resulted in families undertaking much of the necessary burden of care, further increasing household poverty levels (Cohen, 2000; Schoepf, 2001). Consequently southern Africa has received much attention in policy-related and academic literature concerning the plight of those affected by the disease (Barnett and Blaikie 1992; Baylies 2000; Cohen 2000; UNAIDS 2000a; Webb 1997). Within this, children have received special attention as it is often their support providers and caregivers that become infected and gradually weaken through illness, a process which can take several months or years (Barnett and Whiteside 1999; Cohen 2000; Grainger et al 2001; UNAIDS/UNICEF 1999). The impacts of this on children are exacerbated by the nature of the spread of AIDS, which often causes the clustering of infections among families and communities (Nko et al 2000). The result is that some children are removed from school to engage in income-generating activities, caring duties or other household tasks in order to support their families (Bourdillon 1999; Danziger 1994; Kamali et al 1996; Robson 2000).

AIDS-affected children's migration is a further dimension to many household coping strategies (Ansell and Young 2002a). Children may be sent elsewhere to receive care or to work when household members fall sick or die from AIDS, or to assist ailing relatives 
Young L and Ansell N (2003) 'Young AIDS migrants in Southern Africa: policy implications for empowering children' AIDS Care I5(3) 337-345

(Young and Ansell 2002b; see also Ainsworth and Over 1997; Desmond et al 2000; Urassa et al 2001). Although this is having particular impacts on children's lives, policy responses generally pay little or no attention to the migration-related consequences of the epidemic. Instead initiatives have mainly focused on implementing static support mechanisms (for example see MOGYCS/UNICEF 1999).

The majority of policy recommendations suggest methods of best practice for supporting community-based, rather than institutionalised, responses to the AIDS pandemic (Cook et al c2000; Gebru and Atnafou 2000; Munthali and Ali 2000). In particular four main ways for assisting AIDS-affected children are advocated: poverty reduction strategies, building children’s capacities, networking and raising awareness.

Poverty reduction strategies, aimed at communities and families supporting orphans, are intended to ensure that children continue to be cared for within local situations (Krift and Phiri 1998; National AIDS Control Programme 1999). Measures such as income generating activities for families, feeding programmes for vulnerable children and increased access to healthcare and education are viewed as ways of enabling communities to be self-sustaining despite the burden of increasing numbers of orphans (Ainsworth and Over 1997; Grainger et al 2001; Krift and Phiri 1998; Munthali and Ali 2000).

Building children's capacities to enable them to support themselves is also considered good practice and includes assisting them to stay in school, reducing labour demands on children and protecting them from exploitation (Hunter and Williamson c2000). Save the Children UK outline other policy initiatives for capacity building including training teachers to identify traumatised students and provide psychosocial support (Grainger et al 2001). They also advocate the efficient use of community or non-formal schools which are generally locally 
Young $L$ and Ansell N (2003) 'Young AIDS migrants in Southern Africa: policy implications for empowering children' AIDS Care I5(3) 337-345

run and therefore a much cheaper way of ensuring children, forced to drop-out of formal schooling, still receive education (Grainger et al 2001).

Networking and information sharing between local, national and international organisations is also essential for effectively supporting AIDS-affected children (Mwewa 2000). For example, the Lesotho AIDS Programme Co-ordinating Authority (LAPCA) has recently been set up to ensure effective decentralisation of activities among government and nongovernmental organisations and to avoid unnecessary overlap in their efforts to prevent, control and manage HIV/AIDS and orphan care (Government of Lesotho 2000). The experience of the Zambian Children in Need Network has found this to be an effective means for supporting orphans, particularly in relation to advocacy and government lobbying (Mwewa 2000).

Finally, raising awareness among children and communities is an important strategy for reducing HIV infection among young people, and creating a more inclusive community (Grainger et al 2001). Providing information to children helps them to understand the afflictions faced by their families (Human Rights Watch 2001), while sensitising communities fosters an enabling environment for those affected by HIV/AIDS. Promoting understanding and reducing stigma ultimately helps to protect children's safety and rights, including property and inheritance rights (Hunter and Williamson, c2000; Munthali and Ali, 2000).

Family and community-based responses such as these, upheld both nationally and internationally, are important for supporting AIDS-affected children. However, such recommendations tend not to account for the fluidity that exists within extended families and assume that southern African societies are static (Barnett and Whiteside 1999; Letuka et al 1994). It is essential that policy acknowledges that migration is a possible obstacle to 
Young L and Ansell N (2003) 'Young AIDS migrants in Southern Africa: policy implications for empowering children' AIDS Care I5(3) 337-345

successful community responses (UNAIDS 1999), and that the use of children's migration as a coping strategy for dealing with AIDS has resulted in additional burdens being placed on affected children (Young and Ansell 2002a; Young and Ansell 2002b). Therefore, this paper contends that policy responses for assisting AIDS-affected children need to focus more attention on the impacts of AIDS-related migration. By drawing on research conducted with young AIDS migrants in southern Africa, the paper demonstrates the need for including children in decisions that affect their lives. Furthermore, it calls for AIDS-affected children's migration to be considered in policy initiatives, both as a method of empowering children whose families and households have been devastated by the epidemic, and in order to maintain connections between orphaned children and their community heritage.

\section{Methods}

Multi-method research, particularly the use of more qualitative methods, has been called for in relation to AIDS (Akeroyd 1997), migration (McHugh 2000; McKendrick 1999) and children-centred research (Lucchini 1996). This research therefore makes use of a variety of methods: an extensive survey was conducted in order to examine the nature, extent and causes of children's migration which was triangulated with qualitative techniques for a more in-depth insight into young people’s responses and needs.

In order to access the wide ranging experiences of young AIDS migrants in southern Africa, this study was also comparative, contrasting urban and rural communities and Malawi's relative long-standing experience of dealing with HIV/AIDS with the more recent, but rapidly developing, situation in Lesotho. Four communities were therefore selected. In Malawi, Ndirande, a large high density suburb in Blantyre, formed the urban case study, while Mpando, a village located in the Southern Region tea estates of Thyolo district, formed 
Young $L$ and Ansell N (2003) 'Young AIDS migrants in Southern Africa: policy implications for empowering children' AIDS Care I5(3) 337-345

the rural case study. In Lesotho, medium to high density suburbs of Maseru, the capital city, were selected as the urban location while Tlali, a village in the foothills of the Maluti mountains, formed the rural study area.

Children were mainly accessed through local primary schools and 822 children, aged 10 to $17^{1}$ years, participated in a questionnaire and thematic drawing exercise. This extensive part of the research was preceded by a brainstorming session regarding migration, and mainly used as a preparatory exercise for identifying young migrants ${ }^{2}$. To ensure childrencentredness, children were involved in drafting and piloting the questionnaire ${ }^{3}$ (Boyden and Ennew 1997).

The results of the extensive research revealed that $58 \%$ of respondents in Malawi and $40 \%$ in Lesotho had moved at least once. From these approximately 300 young migrants were invited to take part in focus groups, for a more detailed discussion of their migration experiences. From this, a further 65 children took part in making migration storyboards. This allowed the children to define the important aspects of their migration story through pictures, which were subsequently used as prompts for eliciting oral description. In addition, and in order to cover a full range of experiences, focus groups and migration storyboards were undertaken with children residing in institutional care and on the streets.

\footnotetext{
${ }^{1}$ The age of majority is difficult to determine in southern Africa based on different legal and cultural definitions (Rwezaura 1998). In this case, as the research involved children from more than one country and a diverse range of ethnic backgrounds, an upper age limit of 17 was used, based on the legal definition of children in both countries. The lower limit of 10 was used to ensure children had well-informed views concerning migration and were able to compare their migration experiences to those in their place of origin. However, it is acknowledged that younger children also participate in AIDS-related migration.

${ }^{2}$ For ethical and practical reasons, the research was not restricted to those children whose situations were demonstrably related to HIV/AIDS. Although cause of death was discussed, the stigma associated with HIV/AIDS, meant that this was rarely cited as the cause of death. Given that two-thirds of orphans in Malawi and Lesotho are AIDS orphans (Hunter and Williamson 2000), the majority of children's stories related here will be indirectly affected by AIDS.

${ }^{3}$ An initial schedule was drawn up, in both English and the predominant local language, and piloted to a group of twenty students. The children were asked not only to fill in the questionnaire but also to comment on its
} 
Young $L$ and Ansell N (2003) 'Young AIDS migrants in Southern Africa: policy implications for empowering children' AIDS Care I5(3) 337-345

\section{Young AIDS migrants in Lesotho and Malawi}

The research revealed that children sent to live with kin resident elsewhere commonly move over long distances and between urban and rural areas. Children face a range of difficulties associated with migration, particularly integrating into new families and communities. These include making new social contacts, learning new ways of life and dealing with new places. Although these issues are discussed in detail elsewhere (Young and Ansell 2002a; Young and Ansell 2002b), the research identified that those children who coped well with migration were more familiar with the people and places they were moving to. The following extract from Faith's ${ }^{4}$ storyboard demonstrates that visits prior to moving can help to develop this necessary familiarity.

"It was easy for my cousin to fit into our family [after her parents died] because she knew us and often visited here” (Faith's storyboard, Ndirande girl, aged 14)

The children that had negative migration experiences, at least initially, were generally apprehensive about moving because they were going to an unfamiliar environment. They had particular concerns over getting used to new places, which was greatly increased if they also had to adapt to a different way of life such as learning rural agricultural tasks (Young and Ansell 2002b). Children were often worried about fitting in with new people, particularly making new friends, as the following extract from Tsepho's storyboard shows.

\footnotetext{
"When moving... I was anxious and nervous as I wondered how long it would take to get used to the new place and make friends" (Tsepho's storyboard, Tlali, aged 13)
}

structure and content. The children's comments illustrated problems with the wording of certain questions and what information should be omitted or included. In light of this discussion a revised schedule was prepared.

${ }^{4}$ All children's names have been changed to protect their identity. 
Young $L$ and Ansell N (2003) 'Young AIDS migrants in Southern Africa: policy implications for empowering children' AIDS Care I5(3) 337-345

This anxiety was exacerbated by the fact that children were generally not aware of the reasons for sickness and death among their family members nor consulted and informed about their subsequent migration. Stigma associated with HIV/AIDS means that the disease and its consequences are not openly discussed and children are not adequately prepared for their relative's eventual death.

"I don't know what was wrong with my mum but... she looked yellow, lost a lot of weight and had blisters on her hand" (Sechaba's storyboard, Tlali boy, aged 10)

Lack of information is not only confusing for children, but ill prepares them for moving. In general children felt that it is parents' responsibility to make migration decisions for the whole family given that they are usually the main income earners and family supporters. However, following parental death, children's migration usually takes place between a wider network of extended family households, rather than simply as part of nuclear family relocation. In such instances migration decisions were often made by relatives after the parent's funeral, and children were simply told with whom they would live.

\footnotetext{
“When she was dying she didn't tell me who I would live with, she didn't even ask me. (focus group 4, Ndirande boys)
}

"[When my parents died] they [relatives] just came and took us" (focus group 7, Ndirande out of school)

Children felt powerless in these decisions because they had little means to support themselves and felt that in order to receive care they had no choice but to accept whatever their relatives decided.

"A child does not have a say if he refuses to go where he has been told, because 'spilt water is never gathered', maybe there is nowhere else to get assistance...” (focus group 2, Mpando boys) 
Young $L$ and Ansell N (2003) 'Young AIDS migrants in Southern Africa: policy implications for empowering children' AIDS Care I5(3) 337-345

\begin{abstract}
"The death of my father gave me a great shock... My uncle came to take one child to help reduce the number of children my mother had to care for... I went with my uncle to Blantyre to help him. I wasn't really happy but since it was the decision they made... I had to accept” (Anna's storyboard, Ndirande girl, aged 13).
\end{abstract}

"Children have no choice of who to stay with because they may have lost their parents and they have no-one to look after them so they can't choose they just have to follow the one who has come to take them" (focus group 5 , Ndirande boys)

The research found that in several cases children were unhappy with the decisions made, either because they were separated from their siblings or because of difficulties between them and their new guardians. This forced some children to engage in multiple migrations to beg support from more favoured family members or, in extreme cases, to leave the extended family support system altogether and take to the streets (Young and Ansell 2002a).

Severed family ties exacerbate the difficulties faced by those that end up on the streets. The following quote from Thaabe's storyboard demonstrates that street life is often prohibitive to maintaining links with relatives, because of the cost of taking remittances back home, while John's storyboard illustrates the difficulty of returning to live with relatives after becoming accustomed to the freedom earning money provides.

"I saw that my friends were making money in town so I came and when I did I bought paraffin and flour and I took it home, but transport was expensive so I stopped going home” (Thaabe's storyboard, Maseru street boy, aged 17).

"I would like to go back to living in my village in Thyolo because there is my aunt and relatives there. I would learn to do some work like hoeing in the fields. But if I went there I would miss the money I get in town” (John's storyboard, Blantyre street boy, aged 15). 
Young $L$ and Ansell N (2003) 'Young AIDS migrants in Southern Africa: policy implications for empowering children' AIDS Care I5(3) 337-345

Similar difficulties of maintaining community and family ties exist when children have to be cared for institutionally. Although family-type environments are advocated with housemothers caring for particular children (Grainger et al 2001), the opportunities provided by many institutions further removes children from their community heritage.

“I last went home in 1998, I don't know anybody to visit there” (focus group, children’s home Lesotho).

"I will never go back to the way my life used to be, I am happy here. If you go back you... might be sent to initiation schools or we could have been married by now” (focus group, children's home, Lesotho).

In response to this, some governments and other providers of institutional care are now moving towards the principle of maintaining children's links with their extended families. In Malawi, one Blantrye-based organisation sends children back to their villages at weekends and during school holidays, preparing them to live with their relatives once they finish primary school (Interview, Sister Melanie, children’s home, Blantrye, Malawi). Although supported by the orphanage during these visits, the strong links they foster with relatives helps to enable a deeper sense of 'family belonging' among the children.

"When I go to the village at the weekend I always meet my aunt... I am so happy to see her because it's like I have met my real [parent]” (focus group, children’s home, Malawi).

This research has revealed that difficulties faced by young AIDS migrants are complex, depending on the particular situation they find themselves faced with, whether it be moving to live with relatives, onto the streets or into care. Despite this, policy does not adequately address these migration-related problems. The final section of this paper considers ways in which the issues raised here might be dealt with. 
Young L and Ansell N (2003) 'Young AIDS migrants in Southern Africa: policy implications for empowering children' AIDS Care I5(3) 337-345

\section{Policy implications for empowering children: recommendations and}

\section{conclusions}

There is a need to re-focus AIDS policies concerning children given the lack of attention migration is currently afforded. The research discussed here demonstrates that policy approaches need to be more children-centred and take into account the implications of migration at three levels: families enabling children to develop contacts with new people and places prior to migration, parents/guardians empowering children by informing them and involving them in migration decisions, and maintaining children's familial and cultural ties.

Many of the difficulties children face could be overcome if they were more familiar with the place and people they were moving to. Familiarity with foster carers helps to ensure children's AIDS-related migration experiences are positive. Therefore, in order to ease the migration process, policy interventions should support transition strategies for assisting migrant children, including preliminary visits to new places or transition visits with relatives or foster carers prior to migration. By building up such contacts, with the help of their families, children may become less anxious about moving ${ }^{5}$.

Easing the migration process and empowering children can also be achieved by including them in their families’ migration decision-making. Although Ireland and Webb (2001) stress the importance of making children part of the solution, this research illustrates that children are generally left out of such important decisions. It is advocated here that they would be better able to cope with new situations if they were informed about the impacts of AIDS and included in discussions with decision-makers regarding their migration preferences. Grainger

\footnotetext{
${ }^{5}$ This research highlights that it is extended families rather than communities that bear the burden of caring for young AIDS migrants. Despite advocacy for community-based initiatives, in reality communities have little involvement. For this reason, the children-centred recommendations discussed here are situated specifically within the context of families rather than receiving communities (Ansell and Young, 2002b).
} 
Young $L$ and Ansell N (2003) 'Young AIDS migrants in Southern Africa: policy implications for empowering children' AIDS Care I5(3) 337-345

(2001) states that enabling children to accept parents' deaths and to express their fears about the future is important in minimising psychosocial trauma. Within Lesotho there is currently no legislation protecting children who express themselves in opposition to adult authority within the family, although respect for children's views is advocated (NGO Coalition for the Rights of the Child 2000).

It is important to acknowledge here that migration decisions are based on a range of family and personal circumstances. Cultural practices regarding who orphans 'belong' to differ depending on whether societies are patrilineal, as is the case in Lesotho and northern Malawi, or matrilineal, as is the case for many ethnic groups in southern Malawi (Ali 1998; Letuka et al 1994). Further, economic poverty may mean that it is difficult for children to live with the relative of their choice. However, if children are involved in migration discussions, it may be easier for them to understand the decisions made and at least make their feelings known. This would ensure that the best possible solution is achieved, one which is sustainable both from the perspective of the children and the new carers or guardians. Policies that seek to empower children in this way could also result in negotiation between both parties to ensure children's rights are adhered to, particularly with reference to inheritance rights, exploitation and education.

Finally, for those few children who cannot be cared for within families (Hunter and Williamson c2000), it is important that their childhood experience, whether in institutional care or on the streets, does not ostracise them from kin. Maintaining close ties with relatives would ensure that children do not become distanced from their family and cultural heritage. This is essential for post-institutional support and re-integrating children into their communities, particularly given the high cost of caring for children in institutions (Ainsworth and Over 1997). 
Memory books have been used in some countries as a means for parents to prepare children before their death and as a way for children to retain something of deceased family members (Grainger et al 2001). A similar principle could be used to teach children about their cultural heritage through collecting stories and memories from visits home to relatives and as a way of developing close ties with extended family and community members.

In conclusion, this research supports the care of AIDS-affected children by members of the extended family, but suggests that the spatial dislocation that is often involved in such care causes difficulties for young people. Children who have to move to unfamiliar environments, without prior consultation, face particular problems. Those who move out of extended family care are faced with a different, yet still problematic, set of difficulties. Clearly there is a need for policy initiatives to offer support for such children.

\section{Acknowledgements}

This research was funded by the UK Department for International Development (DFID). DFID supports policies, programmes and projects to promote international development. DFID provided funds for this study as part of that objective but the views and opinions expressed are those of the authors alone. The authors would also like to thank two anonymous referees for their comments on this paper. 
Young $L$ and Ansell N (2003) 'Young AIDS migrants in Southern Africa: policy implications for empowering children' AIDS Care I5(3) 337-345

\section{References}

Ainsworth, M and Over, M (1997) Confronting AIDS: public priorities in a global epidemic Oxford University Press, New York

Akeroyd, A V (1997) 'Sociocultural aspects of AIDS in Africa: occupational and gender issues.' in Bond G C, Kreniske J, Susser I and Vincent J (eds) AIDS in Africa and the Caribbean. Westview, Oxford

Ali, S (1998) Community perceptions of orphan care in Malawi, Raising the orphan generation, Pietermaritzburg

Ansell, N and Young, L (2002a) 'Children's migration as a household/family strategy: coping with AIDS in southern Africa' manuscript under review

Ansell, N and Young, L (2002b) 'Enabling households to support successful migration of orphans in southern Africa' manuscript under review

Barnett, T and Blaikie, P (1992) AIDS in Africa: its present and future impact. Belhaven, London

Barnett, T and Whiteside, A (1999) HIV/AIDS in Africa: implications for 'development' and major policy implications, SCUSA Inter-University Colloquium, UEA, Norwich

Baylies, C (2000) 'Overview: HIV/AIDS in Africa: global and local inequalities and responsibilities' Review of African Political Economy 86, 487-500

Bourdillon, M F C (1999) The next generation, Conference on AIDS, livelihood and social change in Africa, Wageningen

Boyden, J and Ennew, J (eds) (1997) Children in focus: a manual for participatory research with children. Radda Barnen, Swedish Save the Children, Stockholm

Cohen, D (2000) Poverty and HIV/AIDS in sub-Saharan Africa, UNDP/SEPED

Cook, P H, Ali, S and Munthali, A (c2000) Starting from strengths: community care for orphaned children in Malawi 
Young $L$ and Ansell N (2003) 'Young AIDS migrants in Southern Africa: policy implications for empowering children' AIDS Care I5(3) 337-345

Danziger, R (1994) 'The social impact of HIV/AIDS in developing countries' Social Science and Medicine 39(7), 905-917

Desmond, C, Michael, K and Gow, J (2000) 'The hidden battle: HIV/AIDS in the household and community' South African Journal of International Affairs 7(2), 39-58

Gebru, M and Atnafou, R (2000) Ethiopia: transitioning from institutional care of orphans to community-based care, International AIDS Conference, Durban, South Africa

Government of Lesotho (2000) Policy framework on HIV/AIDS prevention, control and management, Government of Lesotho, Lesotho

Grainger, C, Webb, D and Elliott, L (2001) Children affected by HIV/AIDS: rights and responsibilities in the developing world Save the Children, London

Human Rights Watch (2001) 'Kenya: in the shadow of death: HIV/AIDS and children's rights in Kenya' Human Rights Watch 13(4(A))

Hunter, S and Williamson, J (c2000) Children on the brink: strategies to support a generation isolated by HIV/AIDS, USAID, Washington, DC

Ireland, E and Webb, D (2001) No quick fix: a sustained response to HIV/AIDS and children, International Save the Children Alliance, London

Kamali, A et al (1996) 'The orphan problem: experience of a sub-Saharan Africa rural population in the AIDS epidemic' AIDS Care 8(5), 509-515

Krift, T and Phiri, S (1998) Developing a strategy to strengthen community capacity to assist HIV/AIDS-affected children and families: the COPE Program of Save the Children Federation in Malawi, Raising the orphan generation, Pietermaritzburg

Letuka, P, Mamashela, M P, Matashane, K, Mbatha, L and Mohale, M (1994) Inheritance in Lesotho. Women and Law in Southern Africa Research Project

Lucchini, R (1996) 'Theory, method and triangulation in the study of street children' Childhood: a global journal of child research (Children out of place: special issue on working and street children) 3(2), 167-170 
Young $L$ and Ansell N (2003) 'Young AIDS migrants in Southern Africa: policy implications for empowering children' AIDS Care I5(3) 337-345

McHugh, K E (2000) 'Inside, outside, upside down, backward, forward, round and round: a case for ethnographic studies in migration' Progress in Human Geography 24(1), 7189

McKendrick, J (1999) 'Multi-method research: an introduction to its application in population geography' Professional Geographer 51(1), 40-50

MOGYCS/UNICEF (1999) Best practices on community-based care for orphans Ministry of Gender, Youth and Community Services, Lilongwe

Munthali, A C and Ali, S (2000) Adaptive strategies and coping mechanisms: the effect of HIV/AIDS on the informal social security system in Malawi, Government of Malawi, National Economic Council, Lilongwe

Mwewa, L (2000) Zambia: the potential of networks of child-focused organizations, International AIDS Conference, Durban, South Africa

National AIDS Control Programme (1999) Malawi national HIV/AIDS strategic framework 2000-2004, The Strategy Planning Unit, National AIDS Control Programme, Ministry of Health and Population, Lilongwe

NGO Coalition for the Rights of the Child (2000) 'Etsa letsete la kamoso, netefatsa litokelo tsa ka': The state of children's rights in Lesotho/ Boema ba litokelo tsa bana Lesotho, Save the Children (UK)

Nko, S, Chiduo, B, Wilson, F, Msuya, W and Mwaluko, G (2000) 'Tanzania: AIDS care learning from experience' Review of African Political Economy 86, 547-557

Robson, E (2000) 'Invisible carers: young people in Zimbabwe's home-based healthcare' Area 32(1), 59-70

Rwezaura, B (1998) 'Competing 'images' of childhood in the social and legal systems of contemporary sub-Saharan Africa' International Journal of Law, Policy and the Family 12, 253-278 
Young $L$ and Ansell N (2003) 'Young AIDS migrants in Southern Africa: policy implications for empowering children' AIDS Care I5(3) 337-345

Schoepf, B (2001) 'International AIDS research in anthropology: taking a critical perspective on the crisis, Annual Review of Anthropology 30, 335-361

UNAIDS (1999) A review of household and community responses to the HIV/AIDS epidemic in the rural areas of southern Africa. UNAIDS, Geneva

UNAIDS (2000a) HIV/AIDS in Africa, UNAIDS, Geneva

UNAIDS (2000b) Report on the global HIV/AIDS epidemic. UNAIDS, Geneva

UNAIDS/UNICEF (1999) Children orphaned by AIDS: front-line responses from eastern and southern Africa.

Urassa, M et al (2001) 'The impact of HIV/AIDS on mortality and household mobility in rural Tanzania' AIDS 15, 2017-2023

Webb, D (1997) HIV and AIDS in Africa Pluto, London

Young, L and Ansell, N (2002a) 'Fragmenting households: children's migration as a response to HIV/AIDS in Malawi and Lesotho' manuscript under review

Young, L and Ansell, N (2002b) 'Moving in the wake of AIDS: children's experiences of migration in Southern Africa' manuscript under review 